\title{
Glicentin 1-61 probably represents a major fraction of glucagon-related peptides in plasma of anaesthetized uraemic pigs
}

\author{
F. G. A. Baldissera and J.J. Holst \\ Institute of Medical Physiology C, The Panum Institute, University of Copenhagen, DK-2200 Copenhagen N, Denmark
}

Summary. Uraemia was induced in pigs by ligation of the renal vascular pedicle, and uraemic plasma was analysed for glucagon and glucagon-related peptides. A preponderance of large molecular weight $\left(\mathrm{M}_{\mathrm{r}}\right)$ components comprising glicentin and moieties of slightly lower $\mathrm{M}_{\mathrm{r}}$ was found, accounting for $73 \pm 3 \%$ (mean \pm SEM, $n=12$ ) of the total plasma glucagonlike immunoreactivity. Comparisons with glicentin 1-61, produced by controlled, stepwise, consecutive digestion of purified natural glicentin with carboxypeptidases (carboxypeptidase A followed by carboxypeptidase B, and again by carboxypeptidase A and B), gel filtration, ion exchange chromatography, reverse phase HPLC and radioimmunoassays for the glucagon sequences 6-15 and 19-29 and for the glicentin sequence 12-30 all indicate that glicentin 1-61 constitutes approximately $57 \%$ of the large $\mathrm{M}_{\mathrm{r}}$ glucagon-related peptides found in uraemia in pigs.

Key words: Glicentin, proglucagon, prohormones, post-translational processing, glucagon metabolism, uraemia.
The kidneys have long been recognized as the major site of glucagon uptake and metabolism [1-7]. Different molecular forms of glucagons or glucagon-like immunoreactivity (GLI) are present in the circulation [7-9]. In hyperglucagonaemic catabolic states such as uraemia, a particular abundance of GLI of molecular weight $\left(\mathrm{M}_{\mathrm{r}}\right) 8000-9000$ is observed [3-6], probably a consequence of decreased renal removal of such compounds [2].

The molecular nature of these components is unknown; we therefore decided to analyse the $8000 \mathrm{Dal}-$ ton GLI, abundant in uraemic plasma, and to investigate its possible relationship to glicentin, a peptide which corresponds to that part of the glucagon precursor in which the glucagon sequence is found [10].

\section{Materials and methods}

Pigs of the LLY-strain (weight $25-30 \mathrm{~kg}$ ) were anaesthetized after an overnight fast, and the renal pedicles were ligated. Twenty-four hours later they were anaesthetized again, and peripheral venous blood was collected into chilled tubes containing $\mathrm{NA}^{++}$-EDTA and Trasylo ${ }^{\circledR}$ $(500 \mathrm{KIU} / \mathrm{ml})$, centrifuged at $4^{\circ} \mathrm{C}$ within $15 \mathrm{~min}$; plasma was kept at $-20^{\circ} \mathrm{C}$ until analysed.

Small aliquots of plasma ( $2.5 \mathrm{ml}$ each) were directly subjected to gel filtration and radioimmunoassays (see below). For concentration of peptides in samples of $20 \mathrm{ml}$ plasma each, a previously described batchwise immunoadsorption technique was employed [11] with Sepharose-coupled antiserum 5618-9 [9] directed against the 6-15 se- quence of the glucagon molecule, thus reacting with any known GLI component. The GLI concentrated on the immunoadsorbent was dissociated with $1.1 \mathrm{~mol} / 1 \mathrm{HCOOH}$ and lyophilized for further analysis.

Gel filtrations were performed on $16 \times 1000 \mathrm{~mm}$ columns (K16/100, Pharmacia Fine Chemicals, Uppsala, Sweden), packed with Sephadex G 50 fine grade (Pharmacia), equilibrated and eluted at $4{ }^{\circ} \mathrm{C}$ with $0.125 \mathrm{~mol} / 1 \mathrm{NH}_{4} \mathrm{HCO}_{3}$, supplemented with $\mathrm{NaCl}$ $(0.1 \mathrm{~mol} / \mathrm{l})$, human serum albumin (Behringwerke, Marburg, FRG, $1 \mathrm{~g} / \mathrm{l})$, merthiolate $(0.6 \mathrm{mmol} / \mathrm{l})$, and adjusted to $\mathrm{pH} 9.0$ with aqueous ammonia. Sample size never exceeded $2 \%$ of bed volume; fractions corresponding to 0.02 bed volumes were automatically collected. Elution positions are described by the coefficient of distribution $\mathrm{K}_{\mathrm{d}}=\left(\mathrm{V}_{\mathrm{e}}-\mathrm{V}_{0}\right) / \mathrm{V}_{\mathrm{i}}$, where $\mathrm{V}_{\mathrm{e}}$ is the elution volume of the substance in question, $V_{0}$ the exclusion volume, and $V_{i}$ the available inner volume, determined as the difference between the elution volumes of ${ }^{125} \mathrm{I}-\mathrm{la}-$ beled human albumin and ${ }^{22} \mathrm{NaCl}$ (The Radiochemical Centre, Amersham, UK), both added to all samples for internal calibration.

Plasma samples of $80-200 \mathrm{ml}$ were subjected to ion-exchange chromatography on a $9 \times 300 \mathrm{~mm}$ column packed with DEAE-Sepharose-CL-6B (Pharmacia). The column was equilibrated and eluted at $4^{\circ} \mathrm{C}$ with $0.05 \mathrm{~mol} / 1$ Tris- $\mathrm{HCl}, \mathrm{pH} 9.0$, and eluted with a $\mathrm{NaCl}$ gradient reaching $0.5 \mathrm{~mol} / \mathrm{l}$ in the same buffer.

Sep-Pak C-18 cartridges (Waters, Milford, Mass., USA) were em ployed for sample concentration and desalting. Samples were concentrated and eluted in one step with $5 \mathrm{ml}$ of $0.1 \%$ trifluoroacetic acid (TFA) of sequanal grade (Pierce Chemical Co, Rockford, Ill., USA) in $61 \%$ ethanol.

Reverse phase gradient HPLC runs were performed on $8 \times 250 \mathrm{~mm}$ columns of Nucleosil ${ }^{\circledR} \mathrm{C}-18$ (particle size $10 \mu \mathrm{m}$ ) employing LKB equipment (2150 HPLC pump, 2152 HPLC controller, 2040-203 low-pressure mixer valve; LKB, Bromma, Sweden). Elution phases were (a): $0.1 \%$ TFA in distilled, deionised water; and (b): $0.05 \%$ TFA in 60\% ethanol (Merck, Darmstadt, FRG, art. N. 11727). Water for HPLC was filtered through a Millex-GS $0.22 \mu \mathrm{m}$ pore size 

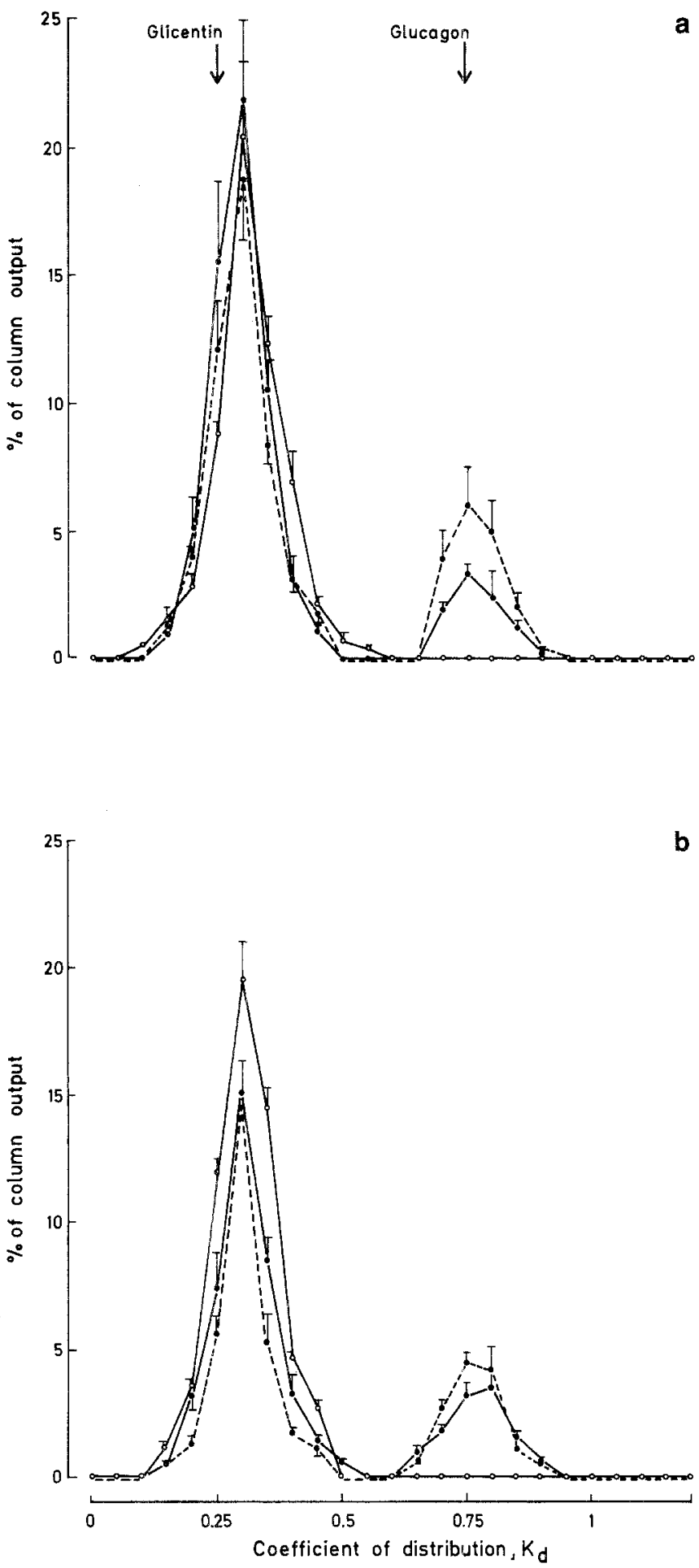

Fig. 1. a average gel filtration profile of untreated plasma. $\mathbf{b}$ average gel filtration profile of plasma samples $(20 \mathrm{ml}$ each) after concentration on the immunoadsorbent ( $\mathrm{n}=6$ in both cases). For each of the coefficients of distribution, $\left(\mathrm{K}_{\mathrm{d}}\right)$-intervals, indicated in the Figure, the glucagon-like immunoreactivity (GLI) concentrations (for each single antiserum) were read from the individual elution curves, by interpolation if necessary, expressed as percentage of the total immunoreactivity eluted from that column, and plotted as mean \pm SEM against the coefficient of distribution, $\mathrm{K}_{\mathrm{d}}$. $(\longrightarrow$ ), glucagon 6-15 immunoreactivity (antiserum 4304); (-- - $)$, glucagon 19-29 immunoreactivity (antiserum 4305); $\left(\mathrm{O}^{-} \mathrm{O}\right)$, glicentin 12-30 immunoreactivity (antiserum $\mathrm{R} 64$ ). The elution positions of glucagon and glicentin standards are indicated by arrows in the figure filter (Millipore S. A., Molsheim, France); the mobile phases were degassed and stored under helium. Sample size for HPLC experiments was $100 \mu \mathrm{l}$ in all cases.

Carboxypeptidase A (CPA) and carboxypeptidase B (CPB) (both from Merck, art. N. 2294 and 2300) were employed for the enzymatic degradation of purified glicentin (The Novo Research Institute, Bagsværd, Denmark). The carboxypeptidases were dissolved in $50 \mathrm{mmol} / 1 \mathrm{Na}$-phosphate buffer, $\mathrm{pH} 8.0$, to a final concentration of $200 \mathrm{U} / \mathrm{ml}$ for CPA and $500 \mathrm{U} / \mathrm{ml}$ for CPB. Purified glicentin $(1.5 \mu \mathrm{g})$ was dissolved in $1 \mathrm{ml}$ of the same buffer, $10 \mu 1$ of the CPA solution was added, and the mixture was incubated at room temperature for $30 \mathrm{~min}$. Ethanol was then added to a final concentration of $61 \%$ to stop the enzymatic digestion; after thorough mixing, human serum albumin was added to a concentration of $0.1 \%$. After mixing and centrifugation at $200 \times g$ for $20 \mathrm{~min}$ at $4^{\circ} \mathrm{C}$, the supernatant was collected, blown dry with $\mathrm{N}_{2}$, and then redissolved in $1 \mathrm{ml}$ of the above mentioned phosphate buffer and degraded by CPB following the same scheme. One subsequent degradation, first with CPA and then with $\mathrm{CPB}$, was carried out as above. After each single step, i.e. after each reconstitution of the dried supernatant in the $50 \mathrm{mmol} / 1$ phosphate buffer, a $10 \mu \mathrm{l}$ sample was taken off for the determination of the 6-15 and the 19-29 glucagon immunoreactivity (see below). The final digest was then studied by gel filtration and reverse phase HPLC.

\section{Radioimmunoassays}

The following assay systems were employed: a) assays for the glucagon sequence $6-15$ with antiserum 4304 , glucagon standards and ${ }^{125}$-Iglucagon, as previously described $[12,13]$; b) assays for the glucagon sequence 19-29 with antiserum 4305 , glucagon standards and ${ }^{125} \mathrm{I}$-glucagon $[12,13]$; $c$ ) assays for the glicentin sequence 12-30 with antiserum R 64 [14], glicentin standards and ${ }^{125}$ I-glicentin [15]. Plasma-coated charcoal was employed for separations [16].

Antiserum 4304 binds labeled and unlabeled glucagon and glicentin with identical affinity $[13,17]$, whereas antiserum 4305 binds the glucagon fragment 19-29 but no other tryptic fragment; e.g. it does not bind turkey glucagon (which is modified at position 28). It also does not bind intact glicentin or other C-terminally extended forms of glucagon, since it requires the glucagon $\mathrm{C}$-terminus to be unextended for binding [13]. Antiserum R 64, directed against the glicentin region 12-30, detects glicentin as well as the glicentin-related pancreatic peptide (GRPP) of pigs [14, 15]. Purified glicentin and glucagon standards, as well as monoiodinated glicentin and glucagon tracers, were kindly donated by Drs. A.J. Moody and U.D. Larsen (The Novo Research Institute, Bagsværd, Denmark).

\section{Statistical analysis}

Results are given as mean $\pm \mathrm{SEM}$, when applicable.

\section{Results}

The gel filtration profile of untreated uraemic plasma ( $2.5 \mathrm{ml}$ samples) is shown in Figure 1, as well as the gel filtration profile of plasma samples of $20 \mathrm{ml}$ each which were previously concentrated by batchwise immunoadsorption. A preponderance of large $\mathrm{M}_{\mathrm{r}}$ components comprising a glicentin-like peptide and moieties of slightly lower $\mathrm{M}_{\mathrm{r}}$, but reacting also with the C-terminally directed antiserum for glucagon, is apparent in both cases. $73 \pm 3 \%$ of the total plasma GLI was composed of these large $\mathrm{M}_{\mathrm{r}}$ GLI (mean $\pm \mathrm{SEM}, n=12$ ). Recovery of the large $M_{r}$ GLI after immunoadsorption and gel filtration was $69 \pm 6 \%$ (mean $\pm \mathrm{SEM}, n=6$ ). 


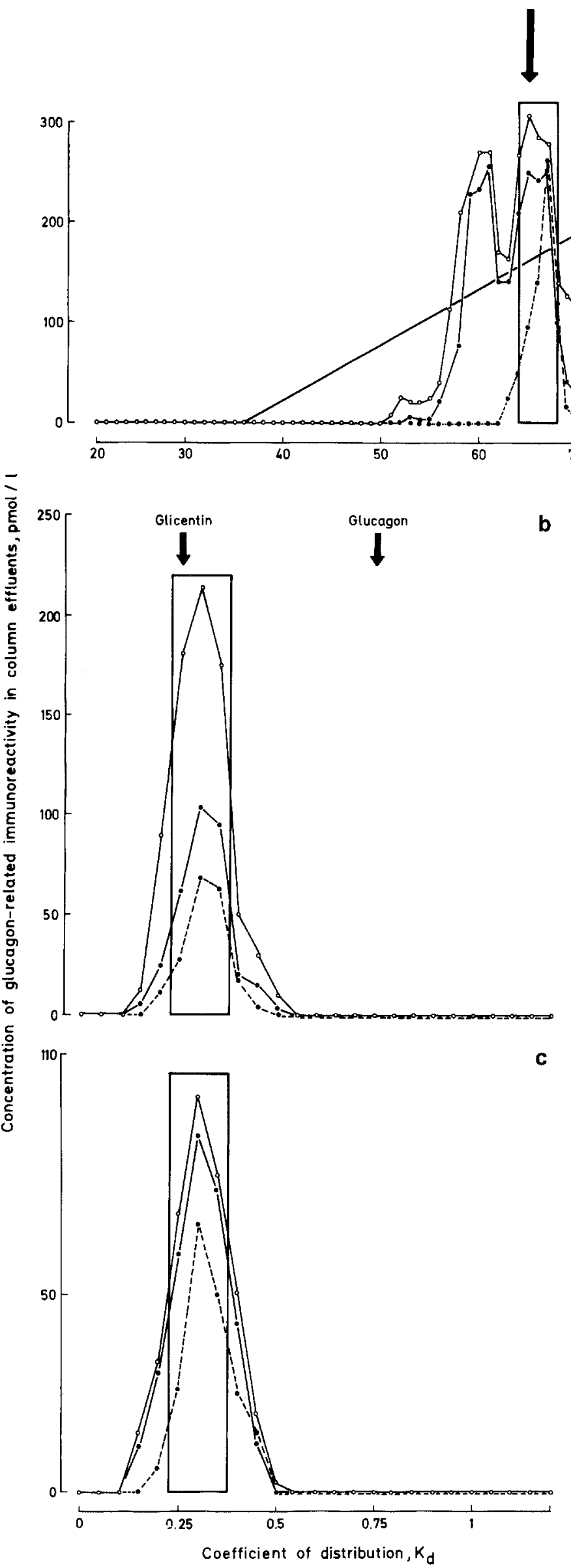

a

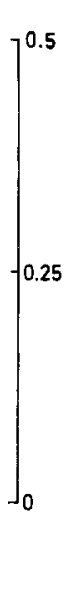

Fig. 2. a Upper panel: Ion-exchange chromatography elution profile of uraemic plasma after concentration by immunoadsorption. The elution position of purified glicentin is indicated by an arrow. (The figure is representative of three similar experiments). b Gel filtration profile of the fractions indicated as box in the upper panel, pooled from three ion-exchange chromatography experiments. $c$ gel filtration profile of the enzymatic digestion product of glicentin after the sequential carboxypeptidase A, carboxypeptidase B, carboxypeptidase A, carboxypeptidase B (CPA-CPB-CPA-CPB) treatment. (-), glucagon 6-15 immunoreactivity (antiserum 4304); (- - ) , glucagon 19-29 immunoreactivity (antiserum 4305); $(\mathrm{O}-\mathrm{O})$, glicentin 12-30 immunoreactivity (antiserum R 64). The elution positions of glucagon and glicentin standards are indicated by arrows in the figure

Larger samples $(80-200 \mathrm{ml})$ were subjected, after immunoadsorption and lyophilization, to ion-exchange chromatography on DEAE-Sepharose.

Two peaks reacting with the antisera for the N-terminally extended GLI are apparent (Fig. 2 a). The first peak shows immunoreactivity for the glicentin sequence $12-30$ and for the glucagon sequence 6-15, and elutes at a ionic strength different from that required for the elution of glicentin (indicated by an arrow); it might therefore be composed of fragments of glicentin, such as glicentin 12-69,1-62 or 1-63, all of which would escape detection with antiserum 4305 and could be formed by trypsin-like digestion of glicentin.

The second peak is heterogeneous. The peptide appearing first, reacting only with antisera R 64 and 4304, and eluting at the same ionic strength of purified glicentin, is probably composed of glicentin itself. A peptide with R 64 and 4304 immunoreactivity as well as immunoreactivity for the glucagon sequence 19-29 (glicentin sequence 51-61, antiserum 4305) eluted somewhat later. This peptide must be composed of a glicentin fragment bearing an exposed C-terminal immunodeterminant of glucagon. Recovery of purified glicentin on this column system was $53 \pm 4 \%$ (mean $\pm \mathrm{SE}$ ).

Fractions from three ion-exchange chromatography experiments, corresponding to the ones indicated as a 


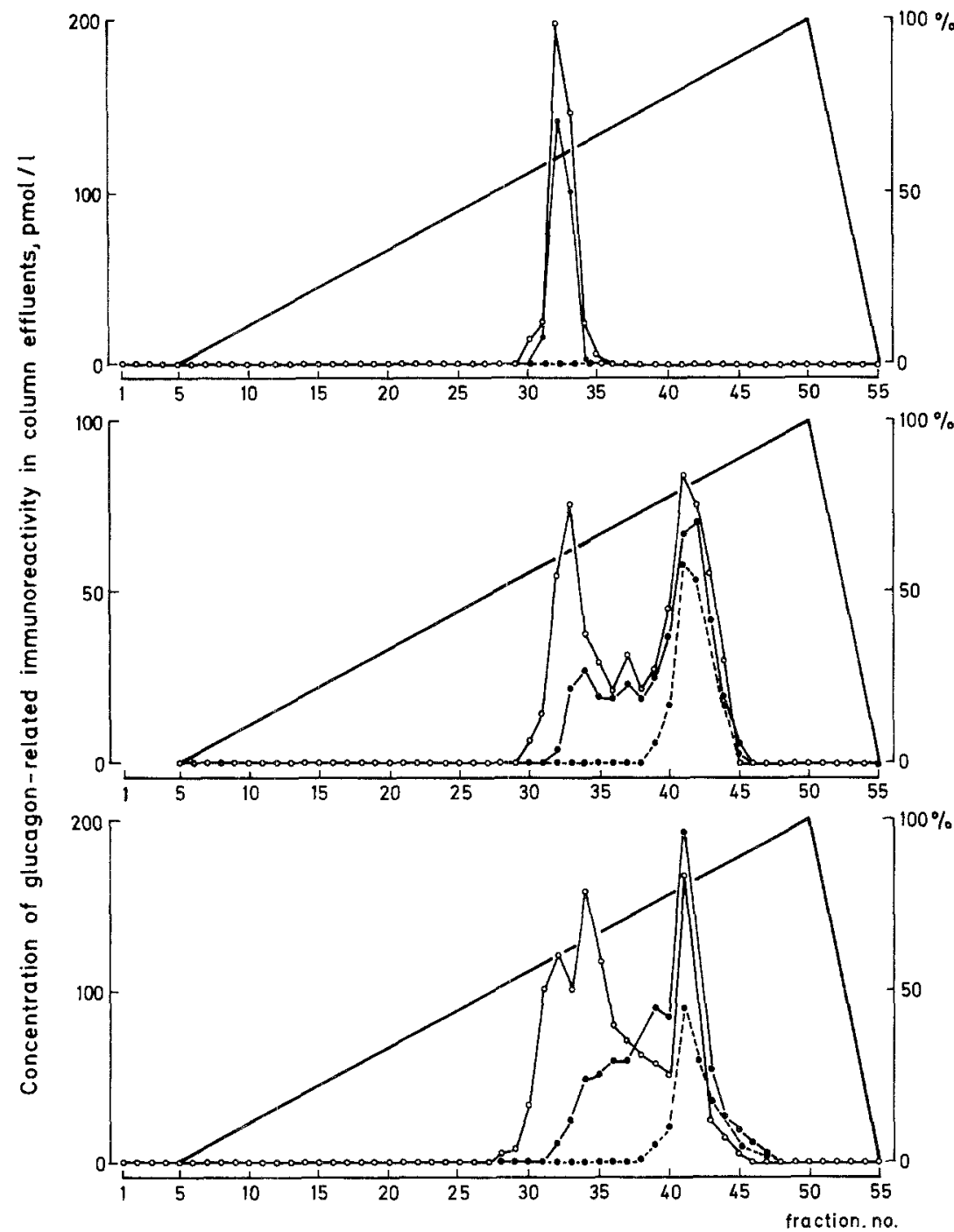

Fig.3. Reverse phase gradient HPLC elutions. Upper panel: purified glicentin. Middle panel: glicentin after the CPA-CPB-CPA-CPB treatment and gel filtration. Lower panel: the peak from the uraemic plasma indicated as box in the gel filtration of Figure 2, middle panel. Eluted fractions were blown dry and subjected to radioimmunoassay. Percentage of phase $B$ in the HPLC elutions $(100 \%$ $\mathrm{B}=0.05 \%$ TFA in $60 \%$ ethanol) is indicated on the 0 to $100 \%$ scale on the right. (The figure is representative of two similar experiments for each of the three samples). ( $\longrightarrow$ ), glucagon 6-15 immunoreactivity (antiserum 4304); ( $\ldots$ ), glucagon 19-29 immunoreactivity (antiserum 4305); ( 0 centin 12-30 immunoreactivity (antiserum R 64) box in Figure $2 \mathrm{a}$, were lyophilized, redissolved in the above mentioned ammonium bicarbonate buffer at pH 9.0 and subjected to gel filtration (Fig. 2 b); a preponderance of $\mathrm{N}$-terminally extended GLI was still apparent.

Peak fractions from these gel filtrations, corresponding to the box in Figure $2 \mathrm{~b}$, were lyophilized, redissolved in $0.1 \%$ TFA in water, passed through and eluted from Sep-PakC-18 cartridges with $5 \mathrm{ml} 0.1 \%$ TFA in 61\% ethanol and lyophilized again for subsequent HPLC analysis.

Purified glicentin was subjected to enzymatic degradation by controlled, consecutive digestions with carboxypeptidase A and carboxypeptidase B. Small amounts of peptide solution removed from each step of the enzymatic degradation of the purified glicentin were serially diluted and assayed for GLI with antisera 4304 and 4305. Antiserum 4304 showed 5732, 4190, 4961, and $4581 \mathrm{pmol} / 1$ after each of the four digestions, respectively, while immunoreactivity could be detected with antiserum 4305 only after the last addition of $\mathrm{CPB}$, the concentration being $3153 \mathrm{pmol} / \mathrm{l}$. The sample obtained after the whole consecutive treatment of purified glicen- tin with carboxypeptidases $\mathrm{A}$ and $\mathrm{B}$ was subjected to gel filtration (Fig. $2 \mathrm{c}$ ); the resulting $\mathrm{K}_{d} 0.30 \mathrm{GLI}$, which now showed strong 4305 immunoreactivity, was lyophilized and subjected to reverse phase HPLC and radioimmunoassay (Fig. 3, middle panel).

Three reverse phase HPLC gradient elutions are shown in Figure 3 ; in the upper panel, purified glicentin; in the middle panel, the products of enzyme-digested glicentin purified by gel filtration (Fig. $2 \mathrm{c}$ ); in the lower panel, the glicentin-like peptides from the uraemic plasma corresponding to the box in Figure $2 b$.

The digestion product of glicentin and the peak from the uraemic plasma were both partially composed of glicentin itself (the R 64 immunoreactive peaks (fractions 30-35) of the middle and lower panel)). The other major peak, with glicentin 12-30 and glucagon 6-15 immunoreactivity (fractions 40-45), also showed clear 4305 immunoreactivity, indicating the presence of an exposed glucagon C-terminal sequence. This peptide accounted for $57 \%$ of the $\mathrm{K}_{\mathrm{d}} 0.30 \mathrm{GLI}$, when analysed for glucagon 6-15 immunoreactivity (antiserum 4304, Fig. 3). 

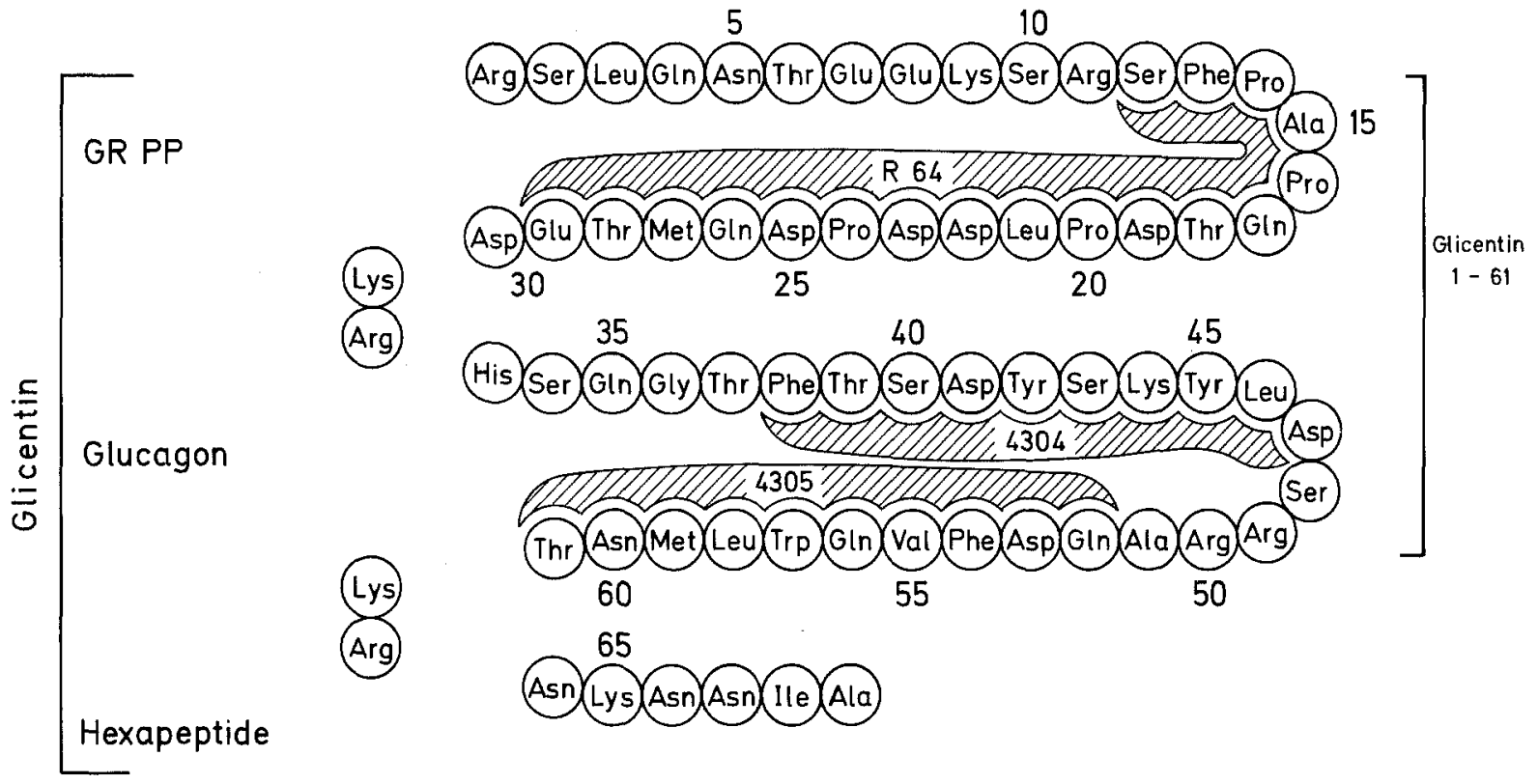

Fig.4. Amino acid sequence of pig glicentin [10]. The suggested sites of cleavage for the generation of glucagon, GRPP [14], and for the glicentin sequence 1-61 are indicated to the left. Binding sites of the antisera employed: antiserum 4304: glicentin sequence 38-47; antiserum 4305: glicentin sequence 51-61; antiserum R 64: glicentin sequence 12-30.

\section{Discussion}

Several molecular forms of glucagon are normally found in the circulation. In uraemia an abnormally large fraction of the total glucagon-like immunoreactivity in plasma has been reported to have a molecular size corresponding to $8000-9000$ dalton $[1,4-7]$.

We also found large amounts of a glucagon-related peptide in the $8000-9000 \mathrm{M}_{\mathrm{r}}$ range in the circulation in uraemic pigs. This was found by simple gel filtration of plasma, and also after specific concentration of plasma GLI by affinity chromatography, which allows a more reliable and precise analysis of the molecular forms.

The glucagon-related peptide of $8000-9000 \mathrm{M}_{\mathrm{r}}$ bears the immunodeterminants for the glicentin sequence 12-30 (antiserum R 64), for the glicentin sequence 38-47 (corresponding to the glucagon sequence 6-15, antiserum 4304) and for the glicentin sequence 51-61 (corresponding to the glucagon sequence 19-29, antiserum 4305); the latter suggests the presence of the C-terminal sequence of the glucagon molecule in its unextended form.

The elution position of this component, representing approximately $56 \%$ of the large $\mathrm{M}_{\mathrm{r}}$ circulating GLI, is $K_{d} 0.30 \pm 0.01$ upon gel filtration, a position slightly, but significantly, different from that of glicentin $\left(\mathrm{K}_{\mathrm{d}} 0.25\right.$ on the same column system, $\mathrm{M}_{\mathrm{r}} 8128[10,12$, 13]).

In view of the structure of proglucagon [18], the above data would suggest that this peptide is a fragment of glicentin corresponding to its 1-61 sequence (Fig.4). In addition, uraemic plasma contained large $M_{r}$ peptides with immunodeterminants corresponding to the glucagon sequence 6-15 (but no C-terminal immunoreactivity).

By ion-exchange purification these plasma components were resolved into two major peaks; the first one, eluting at a ionic strength different from that required for glicentin, may represent a fragment of glicentin itself. The arginine residue at position 11 in the glicentin molecule is a possible cleavage site; therefore, the peptide could correspond to the glicentin sequence 12-69; a peptide with similar chromatographic and immunochemical properties is also found in tissue extracts [17, 19]. On the other hand, the peptide may represent a fragment of glicentin corresponding to either the 1-62 or the $1-63$ sequence.

The other major peak consists of at least two peptides: one corresponding to glicentin 1-69 (left part of the peak), and one with the exposed C-terminal glucagon immunoreactant (fractions 66-68, Fig.2, upper panel). This peptide has all the characteristics to be expected of glicentin 1-61 (Fig. 2, middle panel).

Synthetic glicentin 1-61 was not available for comparative studies. We therefore decided to produce glicentin 1-61 by controlled, stepwise, consecutive degradation of purified natural glicentin with carboxypeptidase A and B. Each single digestion was terminated by the addition of ethanol in a concentration that efficiently blocks enzymatic activities [17]. Carboxypeptidase A and carboxypeptidase $\mathrm{B}$ remove amino acids from the C-terminus of polypeptides; CPA rapidly removes amino acids with aromatic or large aliphatic side chains, while CPB removes the basic amino acids lysine and argine faster than any other common protein amino acid [20]. Thus, theoretically, using CPA first, then CPB, then 
CPA and ending with CPB, it should be possible to remove the C-terminal 8 amino acids from the glicentin molecule, exposing the glucagon $\mathrm{C}$-terminus.

As indicated by the appearance of the $4305 \mathrm{immu}-$ noreactivity (specific for the glucagon sequence 19-29) and from the minimal change in size (from $\mathrm{K}_{\mathrm{d}} 0.25$ to $K_{d} 0.30$ upon gel filtration, Fig. 2 ), the enzymatic digestion was successful. Pure glicentin was not available in sufficient quantities for analysis of amino acid composition or sequence. The digested glicentin fragment eluted, upon gel filtration, at the same position as the 8000 Dalton GLI circulating in the pigs (Fig. 2, middle and lower panels). A further indication of their supposed identity was provided by the radioimmunoassays of the fractions eluted from HPLC (Fig. 3). Both peptides had exactly the same retention time.

The C-terminal hexapeptide of porcine glicentin (residues 64-69) is linked to the first 61 amino acids by the dibasic sequence lysine-arginine, a possible preferential site of post-translational proteolytic cleavage. The glicentin hexapeptide of rat, which differs from the pig at position 65 , was recently reported to be secreted synchronously with glucagon from the pancreas [21].

Thus, we think that the so called "9000 Dalton immunoreactive glucagon" cited by many authors in uraemia or severe renal failure [7] is predominantly composed of the glicentin 1-61 sequence. Its origin is uncertain, however; it could be a pancreatic product $[22,23]$, or it could be derived from GLI producing cells that occur throughout the mammalian gastrointestinal mucosa [19].

Acknowledgements. This investigation was supported by grants from The Danish Medical Research Council, Novo Fond, and Helen og Ejnar Bjørnows Fond. Dr. A.J.Moody, The Novo Research Institute, is thanked for generous gifts of reagents for the glicentin assays.

\section{References}

1. Lefebvre PJ, Luyckx AS, Nizet AH (1974) Renal handling of endogenous glucagon in the dog. Metabolism 23: 753-761

2. Lefebvre PJ, Luyckx AS (1975) Effects of acute kidney exclusion by ligation of renal arteries on peripheral plasma glucagon levels and pancreatic glucagon production in the anesthetized dog. Metabolism 24: 1169-1176

3. Bilbrey GL, Faloona GR, White MG, Atkins C, Hull AR, Knochel JP (1975) Hyperglucagonemia in uremia: reversal by renal transplantation. Ann Intern Med 82: 525-528

4. Kuku SF, Jaspan JB, Emmanouel DS, Zeidler A, Katz AI, Rubinstein AH (1976) Heterogeneity of plasma glucagon circulating components in normal subjects and patients with chronic renal failure. $\mathbf{J}$ Clin Invest 58: 742-750

5. Emmanouel DS, Jaspan JB, Kuku SF, Rubinstein AH, Katz AI, Huen AHJ (1976) Pathogenesis and characterization of hyperglucagonemia in the uremic rat. J Clin Invest 58: 1266-1272
6. Jaspan JB, Rubinstein AH (1977) Circulating glucagon. Plasma profiles and metabolism in health and disease. Diabetes 26: $887-902$

7. Jaspan JB, Polonski KS, Rubinstein AH (1981) The heterogeneity of immunoreactive glucagon in plasma: clinical implications. In: Unger RH, Orci L (eds) Glucagon. Physiology, pathophysiology and morphology of the pancreatic A cell. Elsevier/North Holland, New York, pp 77-96

8. Holst JJ (1983) Molecular heterogeneity of glucagon in normal subjects and in patients with glucagon producing tumors. Diabetologia 24: 359-365

9. Holst JJ, Holst Pedersen J, Baldissera F, Stadil F (1983) Circulating glucagon after total pancreatectomy in man. Diabetologia 25: 396-399

10. Thim L, Moody AJ (1981) The primary structure structure of porcine glicentin (proglucagon). Regul Peptides 2: 139-141

11. Baldissera FGA, Munoz-Perez MA, Holst JJ (1983) Somatostatin 1-28 circulates in human plasma. Regul Peptides 6:63-69

12. Holst JJ (1980) Evidence that glicentin contains the entire sequence of glucagon. Biochem J (London) 187:337-343

13. Holst JJ (1982) Evidence that enteroglucagon (II) is identical with C-terminal sequence (residues 33-69) of glicentin. Biochem $J$ (London) 207:381-388

14. Thim L, Moody AJ (1982) Purification and chemical characterization of a glicentin related pancreatic peptide (proglucagon fragment) from porcine pancreas. Biochim Biophys Acta 703: 134-141

15. Moody AJ, Holst JJ, Thim L, Jensen SL (1981) Relationship of glicentin to proglucagon and glucagon in the porcine pancreas. $\mathrm{Na}$ ture 289: $514-516$

16. Stadil F, Rehfeld JF (1973) Determination of gastrin in serum. An evaluation of the reliability of a radioimmunoassay. Scand J Gastroenterol 8: 101-112

17. Holst JJ (1977) Extraction, gel filtration pattern and receptor binding of porcine gastrointestinal glucagon-like immunoreactivity. Diabetologia 13: 159-169

18. Bell GI, Santerre RF, Mullenbach GT (1983) Hamster pre-proglucagon contains the sequence of glucagon and two related peptides. Nature 302: 716-718

19. Holst JJ (1983) Gut glucagon, enteroglucagon, gut glucagonlike immunoreactivity, glicentin-current status. Gastroenterology 84: $1602-1613$

20. Ambler RP (1967) Enzymic hydrolysis with carboxipeptidases. In: Hirs CHW (ed) Methods in enzymology, vol XI. Academic Press, New York, pp 155-166

21. Yanaihara C, Matsumoto T, Kadowaki M, Iguchi K, Yanaihara N (1985) Rat pancreas contains the proglucagon (64-69) fragment and arginine stimulates its release. FEBS Lett 187:307-310

22. Rigopoulou D, Valverde I, Marco J, Faloona G, Unger RH (1970) Large glucagon immunoreactivity in extracts of pancreas. J Biol Chem 245: 496-501

23. Sheikh SP, Baldissera FGA, Karlsen FØ, Holst JJ (1985) Glicentin is present in the pig pancreas. FEBS Lett 179:1-6

Received: 20 January 1986

and in revised form: 12 May 1986

Dr. Furio G. A. Baldissera

Institute of Medical Physiology C

The Panum Institute

Copenhagen University

Blegdamsvej $3 \mathrm{c}$

DK-2200 Copenhagen $\mathrm{N}$

Denmark 